\title{
A COMPARATIVE STUDY BETWEEN SONOHYSTEROSALPINGOGRAPHY AND HYSTEROSALPINGOGRAPHY IN THE EVALUATION OF INFERTILITY
}

\author{
Saanida. M. P, Beenamol. S.
}

1. Resident, Department of Radiodiagnosis, Medical College, Trivandrum, Kerala.

2. Assistant Professor, Department of Radiodiagnosis, Medical College, Trivandrum, Kerala.

\section{CORRESPONDING AUTHOR}

Beenamol. S.

Assistant Professor,

Department of Radiodiagnosis,

Medical College, Trivandrum, Kerala,

E-mail: beenamols@gmail.com, saanidamp@yahoo.co.in

Ph: 00919995141899,00919495629592

ABSTRACT: OBJECTIVES: Evaluation of uterus, fallopian tubes, ovaries and adnexa with the help of trans-vaginal ultrasonography, and to evaluate the efficacy of SSG as compared to HSG in detecting fallopian tube patency. MATERIALS AND METHODS: Prospective Study of 61 patients for two years in 20-40 yrs age groups referred to Radiology Department in SAT hospital presenting with primary or secondary infertility, All the patients were evaluated with SSG and HSG. Patients with signs of acute genital inflammation or bleeding were excluded from the study. RESULTS: In all the 61 patients presenting with infertility sonosalpingograpy was performed in out of which 46 were primary infertility and 15 were secondary infertility. The detection and characterization of uterine cavity abnormalities was more accurate with SSG than by radiographic HSG. In addition, SSG could detect uterine wall abnormalities, peritoneal abnormalities and ovarian abnormalities which could not be detected on HSG CONCLUSION: Sonohysterosalpingography (SSG) is an effective method for detecting fallopian tube patency. It has a sensitivity of $100 \%$ and a specificity of $84 \%$ with respect to Hysterosalpingography (HSG).The absence of radiation and the fact that it can be performed as an outpatient procedure makes SSG an excellent screening test for evaluation of infertile women.

KEY WORDS: Sonohysterosalpingography, infertility imaging, tubal patency tests

INTRODUCTION: Infertility is defined as involuntary failure to conceive after one year of unprotected sexual intercourse. Infertility affects $15 \%$ of couples ${ }^{3}$.

In the past, the imaging evaluation of the infertile women consisted primarily of Hysterosalpingography (HSG), which remains a mainstay in the diagnosis of uterine and tubal causes of infertility. For example, HSG has been referred to as gold standard in recent studies 8.Earlier work, such as that of Allahbadia ${ }^{1}$, has reported $100 \%$ sensitivity and specificity for HSG where chromopertubation was the gold standard. In recent years, however, there have been advances in the treatment for the various causes of infertility as well as development of new imaging modalities and improvement of old methods.

While vaginal sonography has revolutionized the approach to infertility, transvaginal ultrasound alone provides no information about tubal patency, a characteristic which is of vital importance in the investigation of women complaining of infertility. Even for a hysterographic investigation, distortions of the uterine cavity by either pathological or congenital abnormalities 
can be difficult to assess using sonography. This is especially true when the naturally echogenic endometrium is thin at the beginning of the menstrual cycle.

In order to increase the sensitivity of ultrasound, and to reduce the need for additional investigations, various contrast media have been used. Sterile saline provides an echo - free or negative contrast medium. By applying gentle positive pressure, flow along the tubes and spill into the peritoneal cavity will occur if there is no outflow obstruction. The negative contrast provided by the saline distending the uterine cavity helps in identifying even small intraluminal lesions.

MATERIALS AND METHODS: The present study is a descriptive one based on female patients who presented with complaints of infertility.61 patients were studied over a period of two years who presented to the Obstetrics and Gynecology department at SAT Hospital Trivandrum, with complaints of infertility .The patients were subsequently referred to the department of Radiodiagnosis for the radiological assessment. Written informed consent was obtained from every study patient. Women with signs of acute genital inflammation or bleeding were excluded. All patients were examined by means of a transvaginal approach with a $7.5 \mathrm{MHz}$ transducer (ALOKA SSD - 1000 scanner).

Sterile normal saline was used in SSG to distend the uterine cavity and fallopian tubes and to visualize peritoneal spill.

Urograffin 60 (Diatrizoate meglumine, Diatrizoate sodium) served as the radiographic contrast medium in HSG.

The patient was placed in the lithotomy position, and the vagina was disinfected with an antiseptic solution (Betadine).A speculum examination was then performed. The anterior lip of cervix was held with vulsellum forceps and pediatric Foley's catheter no. 6 or no.8 introduced into the uterine cavity. Bulb of catheter was inflated with $2 \mathrm{ml}$ distilled water. Then the transvaginal probe was inserted for imaging. With the balloon catheter in position, the baseline vaginal sonographic examination without contrast material was done and demonstrated the uterus, pouch of Douglas, and both adnexal regions. During repeat imaging the cavity was filled with saline. Presence of any intracavitory lesion or endometrial abnormalities was noted. To visualize the fallopian tube the probe was focused between the ovary and uterine cornua, and saline was injected upon which tubal patency was assessed by noting the spillage from the fimbrial end. On average a total volume of $20 \mathrm{ml}$ was used.

The criteria studied on SSG were, 1.abnormalities of uterine cavity 2. abnormalities of fallopian tubes. 2. tubal patency - as evidenced by the emergence of saline from the fimbrial end lasting at least 10 seconds in at least one imaged tubal section,3. Peritubal adhesions and 4. Ovarian abnormalities

All patients then underwent conventional Hysterosalpingography, with the findings made by an independent observer, and these findings were then correlated with Sonohysterosalpingography.

RESULTS: The study of sixty one patients who presented with complaints of infertility were first subjected to baseline transvaginal sonography and then sonosalpingograpy. Conventional Hysterosalpingography was done in all sixty one of these patients. The findings in Hysterosalpingography were made by an independent observer.

A clinical history to identify possible predisposing factors leading to infertility and the duration of symptoms were obtained from all the patients. 
The patients were classified into two groups depending on whether they had primary or secondary infertility. Forty six patients had primary infertility, while fifteen patients had history of previous pregnancy.

Immediately after injection of saline, the uterine cavity appeared as an echo - free defined structure within the uterus, oval shaped in transverse section and pear shaped in longitudinal section. Distension of uterine cavity was performed until a resistance was felt in the syringe.

The endometrium appeared as thin, echogenic, homogenous line around the uterine cavity. The myometrium appeared as a thick, homogenous, more refringent structure which formed most of the uterine wall.

After assessment of the uterine cavity more saline was injected to assess tubal patency. Complete visualization of tubal lumen was possible in only 46 out of the 61 cases. In these cases the tubal lumen was visualized on both sides of the uterus as echo - free linear structure. Patency of the tube was diagnosed by visualization of peritoneal spill of saline from the fimbrial end of the tube. In the fifteen cases where visualization was not possible, the tubal block was bilateral in 9 cases while the remaining 6 were unilateral blockages.

In all the 61 patients presenting with infertility sonosalpingograpy was performed in out of which 46 were primary infertility and 15 were secondary infertility. The following diagnoses were made:

- Extra tubal factors on the baseline transvaginal scan -- polycystic ovaries -- were found in $11 \%$ of the cases. Endometrial cysts were found in $15 \%$ of the cases

- Tubal Factors: unilateral tubal block was observed in 10\%, Bilateral tubal block in $15 \%$ and hydrosalpinx was detected in $9 \%$ patients.

One of the important advantages in sonohysterosalpingography was the ability to detect and characterize uterine abnormalities.

CORRELATION WITH HYSTEROSALPINGOGRAPHY: Several studies have been published using echo-free fluid like saline with varying degree of success. This study was done in 61 patients using echo-free normal saline, $7.5 \mathrm{MHz}$ vaginal probe, grayscale imaging. Regarding tubal patency, Sonohysterosalpingography we found that the sensitivity of SSG is $100 \%$, specificity is $84 \%$, while accuracy is $94 \%$. Regarding Uterine abnormalities, sonosalpingograpy was found to be better than Hysterosalpingography

DISCUSSION: Sonohysterosalpingography (SSG) is an effective method for detecting fallopian tube patency. It has a sensitivity of $100 \%$ and a specificity of $84 \%$ with respect to Hysterosalpingography (HSG).The absence of radiation and the fact that it can be performed as an outpatient procedure makes SSG an excellent screening test for evaluation of infertile women. The detection and characterization of uterine cavity abnormalities was more accurate with SSG than by radiographic HSG. In addition, SSG could detect uterine wall abnormalities, peritoneal abnormalities and ovarian abnormalities which could not be detected on HSG.SSG is thus a promising avenue for the investigation of infertility: it is simple, safe and accurate.

Of all couples with infertility, $40 \%$ are attributed to female factors ${ }^{3}$. There are various abnormalities of the uterus and fallopian tubes that lead to infertility, with various modalities to diagnose these. Fallopian tube is a highly sophisticated organ capable of ovum pickup, involved in sperm transport, fertilization and ultimately, transport of zygote into the uterine cavity. Tubal 
factors are involved in $25-40 \%$ of infertile couples ${ }^{3}$. Till recently, diagnostic evaluation in infertility was based on test of tubal patency done by Hysterosalpingography (HSG) and chromolaparascopy. Recently, Sonohysterosalpingography has been used for tubal function studies.

HSG detects only endotubal pathology and sometimes causes allergic manifestations and reactions to the drugs used. Known hydrosalpinx, acute PID or cervicitis, and adnexal mass palpable on manual examination all constitute contraindications to HSG. It also exposes women to radiation. However HSG has the advantage of detecting the site of blockage, isthmica nodosa, benign polyps, and tubal endometriosis.

While laparoscopy is the best technique for diagnosing tubal and peritoneal disease, it is an invasive procedure associated with morbidity and mortality. However, it allows visualization of all the pelvic organs and permits detection of uterine fibroids, peritubal and periovarian adhesions, and pelvic endometriosis.

A subset of our patients ( $\mathrm{n}=17$ ) also underwent laparoscopy. Assuming this selection was random, our sensitivity and specificity for SSG are 100\% each while HSG had $100 \%$ sensitivity and $91 \%$ specificity. We point to the work of Deichertet.al. ${ }^{2}$ as another study with $\mathrm{n}=16$.

With the discovery of ultrasound contrast agents, visualization of the internal genital tract using exogenous contrast medium was first described by Nannini et al.

Sonosalpingograpy is a less time consuming and cost effective noninvasive procedure outpatient procedure, no anesthesia is required and there is no radiation hazard. It helps in the diagnosis of both uterine anomalies and pelvic pathologies. It is reproducible and reliable for assessment of tubal patency. It avoids allergic reactions seen in HSG and tubal patency can be shown to the patients in real time.

The study has disadvantages and limitations. Tubal spasm may lead to the misdiagnosis of tubal occlusion, in hydrosalpinx, tubal flow may give a false impression of tubal patency. Site of the blockage cannot be detected precisely. Intramural pathology is difficult to detect. Peritubal adhesions and motility of the tubes cannot be assessed properly. Moreover it requires a degree of technical competence and the findings are subjective.

SOME OTHER PRACTICAL APPLICATIONS OF SSG ARE: Management of fibroid 6: evaluation of the thickness of the myometrium around an intra-mural fibroid in order to carry out conservative surgery. Examination of myometrial thickness after hysteroscopic resection of myomas. Assess accurately the percentage of protrusion of the volume of fibroid into the endometrial cavity. This information assists in triaging the patient to hysteroscopy or laparoscopy. Sonohysterosalpingography enhanced the diagnostic accuracy of submucous myoma and helps in the decision of the therapy of choice: medical, endoscopy or laparotomy.

Sonohysterosalpingography provides clearer definition and better identification of the site and type of growth (stalked polyp, sessile polyp) of intra-cavitary polyps, thus orienting the therapeutic response.

Sonohysterosalpingography can show evidence of uterine synechiae or confirm uterine malformation. Arcuate uterus can also be diagnosed. Bicornuate uterus may be differentiated from a septate uterus. Thickness and height of the septum is clearly seen.

Radiographic hysterosalpingography provides no information about the ovarian and peritoneal pathology causing infertility where sonosalpingography scores over 
hysterosalpingography. On ultrasound, polycystic ovaries, ovarian hyperstimulation, endometriotic cyst can be detected easily.

Our percentage correlation is $93 \%$ and this matches with Kore et. $\mathrm{al}^{4}{ }^{4}$, who also found that when results of SSG were compared with HSG there was $93 \%$ correlation. A more robust measure of agreement, the kappa statistic, was 0.83 in our study. SSG is thus a promising avenue for the investigation of infertility: it is simple, safe and accurate. Thus, as a diagnostic tool, it establishes tubal patency more effectively than HSG.

\section{REFERENCES:}

1. Allahbadia GN: Fallopian tube patency using color Doppler, Int. J. Gynecol. Obstet. 40 (1993) 241.

2. Deichert U, Schlief R, van de Sandt M, Daume E: Transvaginal Hsterosalpingo-contrast Sonography for the assessment of tubal patency with grayscale imaging and additional use of pulsed wave Doppler. Fertil. Steril. 57 (1992) 62-67.

3. Gaucherand P, Pizcenza JS, Salle B, Rudrigos RC, 'Sonohysterography: Preliminary Investigation', JCU 1992, 28:339-348.

4. Kore S, Hegde A, Nair S, Ambiye VR, Vaidya PR, 'Sonosalpingography for assessment of tubal patency: our experience', J. Obstet Gynaecol India 2000, 50(2):63-66.

5. Landis JR and Koch GG: The measurement of observer agreement for categorical data in Biometrics. Vol. 33, pp. 159-174, 1977.

6. Merchant S, Patil J:transvaginal sonography of the endometrium, in Endosonography in Obstet. Gynecol. Ed. Allahbadia GN 1/e, 1997, 195-206

7. Nannini R, Chelo E, Branconi $\mathrm{F}$ et al.: Dynamic echohyteroscopy. A new diagnostic technique in the study of female infertility. Acta Eur Fertil 1981;12:165-71.

8. Wiesner et. al.Three-dimensional dynamic MR hysterosalpingography: a preliminary report'. European Radiology, 11(8), 2001

TALE - 1 UTERINE ABNORMALITIES DETECTED ON SONOHYSTEROSALPINGOGRAPHY

\begin{tabular}{|c|c|c|}
\hline Abnormality & $\begin{array}{c}\text { Number of } \\
\text { patients }\end{array}$ & Percentage \\
\hline Fibroid & 5 & 8.2 \\
\hline Arcuate uterus & 1 & 1.6 \\
\hline Endometrial polyp & 0 & 0 \\
\hline No abnormality & 55 & 90.16 \\
\hline Total & 61 & 100 \\
\hline
\end{tabular}

TABLE - 2 TUBAL FINDINGS DETECTED ON SONOHYSTEROSALPINOGRAPHY*

\begin{tabular}{|c|c|c|}
\hline Findings & Number of patients & Percentage \\
\hline Bilateral patent tubes & 46 & 75.4 \\
\hline Bilateral tubal block & 9 & 14.7 \\
\hline Right Tube Block & 0 & 0 \\
\hline Left Tube Block & 6 & 9.8 \\
\hline Bilateral Hydrosalpinx & 2 & 3.7 \\
\hline Unilateral Hydrosalpinx & 3 & 5.5 \\
\hline Total & 61 & 100 \\
\hline
\end{tabular}


TABLE - 3 COMPARISON BETWEEN SONOHYSTEROSALPINGOGRAPHY AND HYSTEROSALPINGOGRAPHY IN CONDITIONS DETECTED AT CHROMOPERTUBATION/LAPARASCOPY*

\begin{tabular}{|l|c|c|c|}
\hline \multicolumn{1}{|c|}{ Condition } & SSG & HSG & Found at Surgery \\
\hline Bilateral Patent & 11 & 10 & 11 \\
\hline Bilateral Block & 4 & 5 & 4 \\
\hline Unilateral Left Block & 2 & 2 & 2 \\
\hline Unilateral Right Block & 0 & 1 & 0 \\
\hline Peritubal Adhesion & 1 & 0 & 3 \\
\hline Endometriosis & 2 & 0 & 2 \\
\hline Polycystic Ovaries & 2 & 2 & 2 \\
\hline
\end{tabular}

*A subset of 24 patients from the total 61 underwent chromopertubation/laparoscopy.

TABLE - 4 COMPARISON BETWEEN SONOHYSTEROSALPINGOGRAPHY AND RADIOGRAPHIC HYSTEROSALPINGOGRAPHY IN EVALUATION OF TUBALPATENCY

\begin{tabular}{|l|l|l|l|}
\hline & \multicolumn{4}{|l|}{ HYSTEROSALPINGOGRAPHY } \\
\hline Sonohysterosalpingography & Patent & Not patent & Total \\
\hline Patent & 42 & 4 & 46 \\
\hline Not patent & 0 & 15 & 15 \\
\hline Total & 42 & 19 & 61 \\
\hline
\end{tabular}

TABLE-5 CHI-SQUARE TESTS FOR CORRELATION BETWEEN SONOHYSTEROSALPINGOGRAPHY AND HYSTEROSALPINGOGRAPHY

\begin{tabular}{|l|l|l|l|l|l|}
\hline & Value & Df & Asymp. Sig. (2sided) & $\begin{array}{l}\text { Exact Sig. } \\
(2 \text {-sided })\end{array}$ & $\begin{array}{l}\text { Exact Sig. } \\
(1 \text {-sided })\end{array}$ \\
\hline Pearson Chi-Square & $43.970(\mathrm{~b})$ & 1 & .000 & & \\
\hline Continuity Correction(a) & 39.816 & 1 & .000 & & \\
\hline Likelihood Ratio & 48.493 & 1 & .000 & & \\
\hline Fisher's Exact Test & & & & .000 & .000 \\
\hline No of Valid Cases & 61 & & & & \\
\hline
\end{tabular}

(a) Computed only for a $2 \times 2$ table

(b) 1 cells $(25.0 \%)$ have expected count less than 5 . The minimum expected count is 4.67 .

Inference: The corrected value of correlation is 39.8 , which indicates very high correlation between sonohysterosalpingography and hysterosalpingography.

TABLE -6 CORRELATION MEASURES TO COMPARE SONOHYSTEROSALPINOGRAPHY AND HYSTEROSALPINGOGRAPHY

\begin{tabular}{|l|l|l|l|l|}
\hline & Value & Asymp. Std. Error(a) & Approx. T(b) & Approx. Sig. \\
\hline $\begin{array}{l}\text { Measure of Agreement Kappa } \\
\text { \%-age correlation }\end{array}$ & $\begin{array}{l}.838 \\
93.4 \%\end{array}$ & .077 & 6.631 & .000 \\
\hline
\end{tabular}

(a) Not assuming the null hypothesis. 
(b) Using the asymptotic standard error assuming the null hypothesis.

Inference: Kappa value greater than .81 is held to be in 'almost perfect agreement'. Here it is approximately .84 . The percentage correlation is also high at $93.4 \%$. 